\title{
Spk1/Rad53 is regulated by Mec1-dependent protein phosphorylation in DNA replication and damage checkpoint pathways
}

\author{
Zhaoxia Sun, ${ }^{1,2}$ David S. Fay, ${ }^{1}$ Federica Marini, ${ }^{3}$ Marco Foiani, ${ }^{3}$ and David F. Stern ${ }^{1,4}$ \\ ${ }^{1}$ Department of Pathology, Yale University School of Medicine, New Haven, Connecticut 06520-8023; ${ }^{2}$ Department of \\ Biology, Yale University, New Haven, Connecticut 06520-8103 USA; ${ }^{3}$ Dipartimento di Genetica e di Biologia dei \\ Microrganismi, Universita' degli Studi di Milano, Milan, Italy
}

\begin{abstract}
SPK1/RAD53/MEC2/SAD1 of Saccharomyces cerevisiae encodes an essential protein kinase that is required for activation of replication-sensitive and DNA damage-sensitive checkpoint arrest. We have investigated the regulation of phosphorylation and kinase activity of Spk1p during the cell cycle and by conditions that activate checkpoint pathways. Phosphorylation of $S p k 1 p$ is induced by treatment of cells with agents that damage DNA or interfere with DNA synthesis. Although only $S$ - and $G_{2}$-phase $c d c$ mutants arrest with hyperphosphorylated Spk1p, damage-induced phosphorylation of Spk1p can occur in $G_{1}$ and $M$ as well. Hydroxyurea (HU) induces phosphorylation of kinase-defective forms of Spk1p, demonstrating that this regulated phosphorylation of Spk1p occurs in trans. HU-induced phosphorylation is associated with increased catalytic activity of Spk1p. Furthermore, overexpression of wild-type $S P K 1$, but not checkpoint-defective alleles, delays progression through the $G_{1} / S$ boundary. Damage-dependent phosphorylation of Spk1p requires both $M E C 1$ and $M E C 3$, whereas $M E C 1$ but not $M E C 3$, is required for replication block-induced phosphorylation. These data support the model that $\mathrm{Spk} 1 \mathrm{p}$ is an essential intermediate component in a signal transduction pathway coupling damage and checkpoint functions to cell cycle arrest. This regulation is mediated through a protein kinase cascade that potentially includes Meclp and Tellp as the upstream kinases.
\end{abstract}

[Key Words: Saccharomyces cerevisiae; DNA damage; checkpoint pathway; SPK1/RAD53/MEC2/SAD1; MEC1]

Received October 27, 1995; revised version accepted Deccmber 29, 1995

The integrity of the genome is under constant assault through errors in replication and chromosome mechanics, and through the action of extrinsic mutagens. Prokaryotic and eukaryotic cells have evolved a network of mechanisms for minimizing the consequences of DNA damage. Basal and damage-inducible DNA repair systems are called into play by an array of DNA lesions. Damage-regulated checkpoint controls are important elcments of the cellular response to DNA lesions and presumably work by providing enough time for the operation of DNA repair systems. In parallel, replication-sensitive checkpoint controls may be important to ensure that cells remain in S until replication is complete. Failure of these cell cycle restraints can increase mutation rates and genomic instability, which can lead to cancer in humans (Hartwell and Kastan 1994).

p53, the most frequently mutated tumor suppressor gene, is required for damage-regulated arrest at the $G_{1} / S$ checkpoint (Lane 1992). A second human checkpoint gene, $A T M$, is also a tumor suppressor gene. ATM mu-

${ }^{4}$ Corresponding author. tations cause the ataxia telangiectasia (AT) syndrome, which is characterized by a number of defects including greatly elevated cancer risk (for review, see Meyn 1995). Cells from AT individuals are hypersensitive to ionizing radiation and fail to show normal damage-induced cell cycle arrest. The ATM gene seems to operate upstream from p53 and is homologous to a gene family including lipid and protein kinases (Kastan et al. 1992; Lehmann and Carr 1995; Savitsky et al. 1995). Significantly, ATM is structurally homologous to budding yeast TEL1 and MEC1, and fission yeast rad3 + (Kato and Ogawa 1994; Greenwell et al. 1995; Savitsky et al. 1995; Zakian 1995). The latter two have DNA checkpoint functions, indicating a functional homology. Hence, the identification of the human damage checkpoint gene ATM forged a link with the genetic analysis of checkpoint control pathways in yeasts.

Multiple DNA-related checkpoint pathways have been identified in Saccharomyces cerevisiae. When DNA is damaged, these controls prevent cells in $\mathrm{G}_{1}$ from entering $S$ phase, cells in late $S$ or $G_{2}$ phase from undergoing mitosis, and they also retard $S$ phase progression (Weinert and Hartwell 1988; Hartwell and Weinert 1989; 
Siede et al. 1993; Paulovich and Hartwell 1995). Another checkpoint prevents cells with incompletely replicated DNA from exiting S phase (Hartwell and Weinert 1989; Murray 1992). Three distinct sets of DNA checkpoint genes have been identified in $S$. cerevisiae. One set, including $M E C 3, R A D 9$, and $R A D 24$, is required for function of the damage-regulated $G_{1} / S$ and late $S / G_{2}$ checkpoints, and is dispensable for the S-phase replication checkpoint (Siede et al. 1993; Weinert et al. 1994). A second set, defined by dun alleles of $P O L 2$, is required for the S-phase checkpoint but is unnecessary for the damage checkpoints (Navas et al. 1995). Finally, the two essential genes MEC1 and SPK1/RAD53/SAD1/MEC2 are necessary for both damage-regulated and replication checkpoints (Allen et al. 1994; Weinert et al. 1994).

SPK1 encodes a protein kinase that is located primarily in the nucleus (Stern et al. 1991; Zheng et al. 1993). $S P K 1$ is activated transcriptionally near the $G_{1} / S$ boundary. This regulation is probably conferred by a pair of consensus Mlu1 cell cycle box (MCB) regulatory elements such as those found in a number of genes transcribed in $S$ phase including DNA synthetic enzymes and cyclins Clb5 and Clb6. Other upstream sequences similar to DNA damage response elements suggested that $S P K 1$ is involved in the DNA damage response (Zheng et al. 1993). SPK1, like MEC1, is required for the activation of DNA damage-induced checkpoints in $G_{1}$ and $G_{2}$ and for the induction of the $S$ phase checkpoint, as partial loss-of-function mutants are defective in these processes (Allen et al. 1994; Weinert et al. 1994). In addition, SPK1 is required for the transcriptional stimulation of DNA repair genes RNR2 and RNR3 (Allen et al. 1994). This is genetically distinguishable from the checkpoint response, as dun 1 cells are checkpoint competent (Zhou and Elledge 1993). Finally, the nuclear localization, transcriptional regulation, and terminal arrest phenotypes of spk1d null mutants raised the possibility that the essential function of Spklp is associated with DNA replication (Zheng et al. 1993). Hence, Spk lp may be a pleiotropic regulator of both DNA replication and the damage response.

The distinct phenotypes of RAD9-like genes and POL2 (dun2)-like genes has led to the model that each set defines an independent signaling pathway activated by either DNA damage or partly replicated DNA. The common phenotypes of $s p k 1$ and mec1 and the fact that they are required for both sets of checkpoints might mean that these genes are involved in both sets of recognition processes or, alternatively, that they function in a common pathway downstream from the recognition pathways and couple those pathways to cell cycle arrest (Allen et al. 1994; Weinert et al. 1994). Although these models are consistent with current data, there is virtually no direct evidence to verify them. For the most part, the existence of these pathways has been inferred from common mutant phenotypes, rather than genetic or biochemical epistasis experiments. For example, there is no direct evidence that Spklp and Meclp act in the same pathway or that either is regulated by DNA replication or DNA damage.
As a first step toward biochemically defining these checkpoint pathways, we have investigated the regulation of Spklp in the cell cycle and in response to induction of checkpoint arrest. We show here that Spk1p phosphorylation is regulated by damage and replication checkpoints. Activation of Spklp through overexpression is sufficient to inhibit cell cycle progression at the $\mathrm{G}_{1} / \mathrm{S}$ boundary. The results suggest that Meclp and Spklp participate serially in a linear damage- and replication-regulated pathway in which Spklp is regulated in a protein kinase cascade.

\section{Results \\ Cell cycle regulation of Spk1p abundance and modification}

Initially, SPK1 transcripts are very low in $\mathrm{G}_{1}$ arrested cells and increase to maximal levels as cells enter $S$ phase (Zheng et al. 1993). This apparent cell cycle regulation may be misleading, however, as the majority of MCB gene products give rise to stable proteins that do not fluctuate much during the cell cycle (McIntosh 1993|. Therefore, we examined Spk1p abundance in a population of cells synchronized at Start and then released into $G_{1}$ (Fig. 1). Growth of strain 1608-21C (cln1 1 , $\operatorname{cln} 2 \Delta, \operatorname{cln} 3 \Delta, G A L 1-C L N 3$ ) (Table 1 | is strictly regulated by galactose induction of $C \ln 3 p$. These cells arrest uniformly at Start in raffinose and proceed synchronously through the cell cycle after induction with galactose. Spklp was present at Start and increased substantially 30 min after release from Start arrest, coincident with the emergence of small budded cells (Fig. 1A). Spk1p levels were sustained until $70 \mathrm{~min}$, when large budded cells first appear \{Fig. 1A\}. This timing is consistent with an S phase-specific increase in Spk $1 p$ levels and is consonant with RNA analysis (Zheng et al. 1993). In contrast to the mRNA, however, Spklp was present in significant quantities at Start, suggesting that Spklp is more stable than SPK1 mRNA.

In subsequent experiments with a different antibody preparation and different electrophoresis conditions, Spk1p resolved into multiple species (Fig. 1B). A lower mobility form appeared in parallel with small budded cells. [The sample for the $40 \mathrm{~min}$ time point was evidently lost, as Spklp persisted and remained shifted in other experiments (Fig. 1C).] After 60 min Spklp reverted to the lower molecular weight singlet form in parallel with the appearance of large budded cells (Fig. IB). Spk $1 p$ remained in singlet form as cells divided and entered the next $G_{1}$ (data not shown). Because cell cycle progression driven by CLN3 overexpression in a triple cln disruption background may be abnormal, we carried out similar experiments in which isogenic wild-type cells (1255-5C) were synchronized with $\alpha$-factor. Under these conditions, the Spklp mobility shift was not detected (data not shown). This negative result may have resulted from poorer synchrony or may mean that the 
Table 1. Plasmids and strains used in this study

\begin{tabular}{|c|c|c|}
\hline Plasmid/Strain ${ }^{\mathrm{a}}$ & Description/Genotype & Source \\
\hline pNB187 & YCp50 (URA3, ARS1, CEN4) with GAL1 promoter & P. Novick ${ }^{\mathrm{b}}$ \\
\hline $\mathrm{pNB} 187-S P K 1$ & $S P K 1$ coding sequences behind GAL1 promoter in pNB 187 & c \\
\hline pNB187-spk1K227A & spk $1 \mathrm{~K} 227 \mathrm{~A}$ coding sequences behind GAL1 promoter in pNB 187 & c \\
\hline pNB187-spk1-1 & spk1-1 coding sequences behind GAL1 promoter in pNB187 & $\mathrm{d}$ \\
\hline $316 \$ P K 1$ & $S P K 1$ (EcoRI fragment) in pRS316 & e \\
\hline $316 \operatorname{spk} 1 \mathrm{~K} 227 \mathrm{~A}$ & spk1K227A (EcoRI fragment) in pRS316 & d \\
\hline $316 \operatorname{spk} 1 \mathrm{~A} 208 \mathrm{P}$ & spk1A208P (EcoRI fragment) in pRS316 & d \\
\hline 316 spk1D339A & spk1D339A(EcoRI fragment) in pRS316 & d \\
\hline $316 \operatorname{spk} 1 \mathrm{D} 339 \mathrm{~A} / \mathrm{K} 227 \mathrm{~A}$ & spk1D339A/K227A (EcoRI fragment) in pRS316 & d \\
\hline $1608-21 \mathrm{C}$ & MATa bar 1 cln $1:: T R P 1$ cln $2 \Delta \operatorname{cln} 3 \Delta$ leu2::LEU2::GAL1::CLN3 & F. Cross ${ }^{\mathrm{e}}$ \\
\hline $1255 \cdot 5 \mathrm{C}$ & MATa bar1 CLN1 CLN2 CLN3 & F. Cross ${ }^{e}$ \\
\hline NY605 & MATa leu2-3,112/ + ura3-52/ura3-52 his4-619/+ & P. Novick (pers. comm.) \\
\hline NY882 & $\begin{array}{l}\text { MATa/MATa ura3-52/ura3-52 leu2-3,112/leu2-3,112 } \\
\text { his3- } \Delta 200 / \text { his- } \Delta 200 \text { LYS2-801/ + ade4l+ }\end{array}$ & P. Novick (pers. comm.) \\
\hline DZ6 & MATa/MATa spk $1 \triangle X B:: H I S 3 /+$; disruption of NY882 & d \\
\hline $\mathrm{DZ} 413$ & MATo spk1 $\triangle X B:: H I S 3$; segregant from sporulation of DZ6-1 & d \\
\hline h9clal & MATa his7 ura1 cdc9-1 & L. Hartwell ${ }^{f}$ \\
\hline h5clbl & MATa his7 ural cdc5-1 & L. Hartwell ${ }^{f}$ \\
\hline h28c4al & MATa cdc28-4 his7 ura1 & L. Hartwell ${ }^{f}$ \\
\hline h4clal & MATa cdc4-1 his 7 ura1 & L. Hartwell ${ }^{f}$ \\
\hline h $7 \mathrm{c} 4 \mathrm{al}$ & MATa $c d c 7-4$ his 7 ura1 & L. Hartwell ${ }^{f}$ \\
\hline h2c2al & MATa cdc2-2 his7 ura1 & L. Hartwell ${ }^{\mathrm{f}}$ \\
\hline h8clal & MATa $c d c 8-1$ his 7 ura1 & L. Hartwell ${ }^{f}$ \\
\hline h17clal & MATa $c d c 17-1$ his 7 ura1 & L. Hartwell ${ }^{f}$ \\
\hline hl6clal & MATa cdc16-1 his7 ura1 & L. Hartwell ${ }^{\mathrm{f}}$ \\
\hline 2593 & MATa ade1 ade2 gal1 his1 lys2 tyr1 ura1 cdc20-2 & $\begin{array}{l}\text { K. Nasmyth and } \\
\text { L. Hartwell }\end{array}$ \\
\hline TWY 146 & MAT $\alpha$ cdc13-1 ura3 his7 & T. Weinert ${ }^{\mathrm{g}}$ \\
\hline TWY148 & MATa cac13-1 mec2-1 ura3 his7 & T. Weinert ${ }^{\mathrm{g}}$ \\
\hline TWY158 & MATa cdc13-1 mec1-1 ura3 his7 & T. Weinert ${ }^{g}$ \\
\hline TWY159 & MAT $\alpha$ cdc13-1 mec3-1 ura3 his7 & T. Weinert ${ }^{\mathrm{g}}$ \\
\hline TWY446 & MATa $c d c 17-1$ his 7 & T. Weinert ${ }^{g}$ \\
\hline TWY447 & MAT $\alpha$ cdc17-1 mec1-1 trp1 & T. Weinert ${ }^{8}$ \\
\hline TWY448 & MATa $c d c 17-1$ mec2-1 his 7 & T. Weinert ${ }^{\mathrm{y}}$ \\
\hline TWY449 & MAT $\alpha$ cdc17-1 mec3-1 ural ura3 his 7 trp1 & T. Weinert ${ }^{\mathrm{B}}$ \\
\hline TWY397 & MATa ura3 his7 leu2 trp 1 & T. Weinert ${ }^{\mathrm{h}}$ \\
\hline K699 & MATa ura3-52 leu2-3,112 trp1-1 ade2-1 can1-100 his3-11,15 GAL psi & $\begin{array}{l}\text { K. Nasmyth (Research } \\
\text { Institute of Molecular } \\
\text { Pathology,Vienna, } \\
\text { Austria) }\end{array}$ \\
\hline 1082 & MAT $\alpha$ trp ade leu ura lys tyr cdc14-3 & K. Nasmyth \\
\hline 1081 & MATa ade1 ade2 ura1 tyr 1 his 7 lys 2 gal1 cdc15-4 & K. Nasmyth \\
\hline $\mathrm{ZY} 35-34 \mathrm{~A}$ & MATa ade2 ura3 leu2 trp1 his 3 cdc $34-2$ & $\begin{array}{l}\text { D. Gonda (Department of } \\
\text { Molecular Biophysics and } \\
\text { Biochemistry, Yale } \\
\text { University School } \\
\text { of Medicine, } \\
\text { New Haven, CT) }\end{array}$ \\
\hline $\mathrm{Y} 203$ & MATa ade2-1 his3 leu2-3,112 lys2 trp1 ura3-A100, mr3:-RNA3-URA3-LEU2 & S. Elledge $\mathrm{e}^{\mathrm{i}}$ \\
\hline
\end{tabular}

${ }^{a} 1608-21 \mathrm{C}$ and $1255-5 \mathrm{C}$ are isogenic derivatives of BF264-15D (trp1-1a leu2-3,112 ura3 ade1 his2). 2593 originated from an A364a background. Stains from L. Hartwell or T. Weinert are isogenic with A364a. K699 is the same as W303. 1082 and 1081 have been crossed to W303 background and are from K. Nasmyth. ZY35-34A is isogenic with YMW1. Y203 is isogenic with XS955-36B.

${ }^{\mathrm{b}}$ Salminen and Novick (1989).

'Zheng et al. (1993).

${ }^{d}$ D.S. Fay and D.F. Stern (in prep.).

eLambertus and Cross (1994).

fWeinert and Hartwell (1993).

sWeinert et al. (1994).

${ }^{\mathrm{h}}$ Weinert and Hartwell $\{1990$ !.

iZhou and Elledge (1993). 
Sun et al.

A

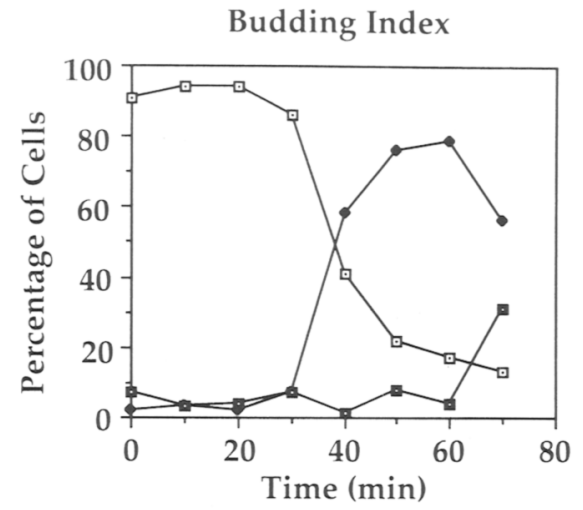

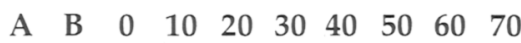

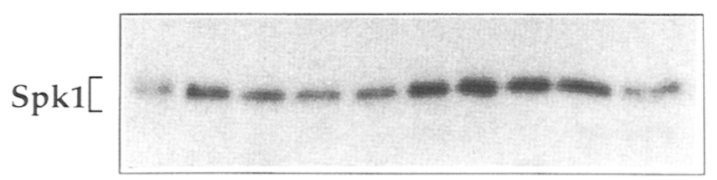

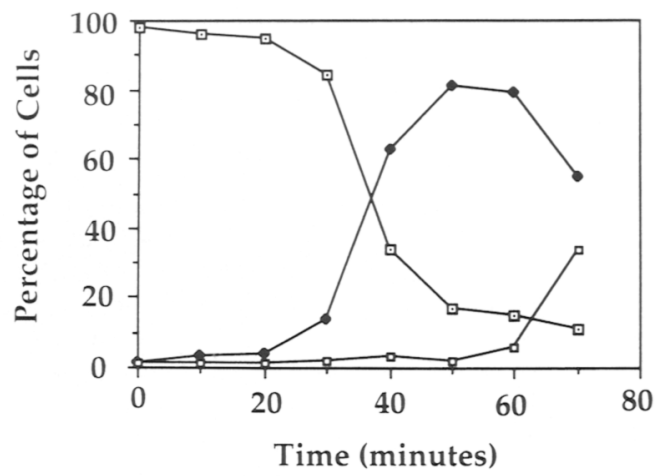

$\begin{array}{llllllll}0 & 10 & 20 & 30 & 40 & 50 & 60 & 70\end{array}$

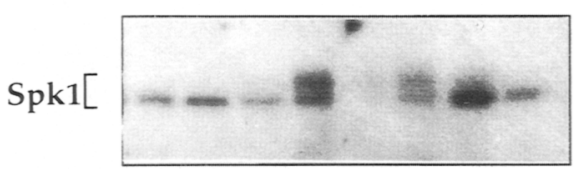

C

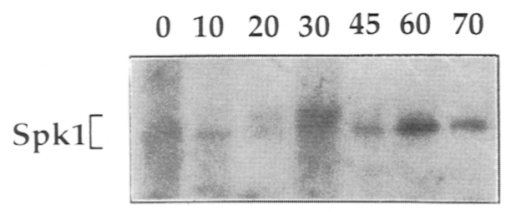

Figure 1. Cell cycle regulation of Spklp. (A) Regulation of Spkip levels during cell cycle. 1608-21C cells were grown in YPG and then washed and resuspended in YPR. Cells were incubated in YPR for $2.5 \mathrm{hr}$ until uniformly arrested at Start. Galactose was then added to a final concentration of $3 \%$ (wt/vol) Samples were removed at the indicated times for morphological inspection (top) and consecutive immunoprecipitation and immunoblotting with anti-Spklp (bottom) as described in Materials and methods. (Lane A) Immunoprecipitated overexpressed Spk lp from NY605 SPK1 cells; (lane B) immunoprecipitated Spk1p from log-phase 1608-21C cells. Other lanes are Spklp at the indicated times

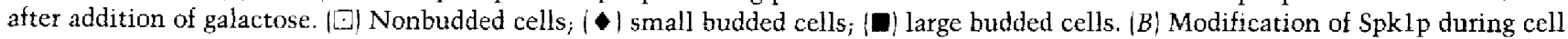
cycle progression. This is similar to the experiment in $A$, but Spklp was immunoprecipitated and immunoblotted with a different polyclonal antibody preparation, and electrophoresis was substantially slowed down to $5 \mathrm{~mA}$ constant current. (Top) Budding indices; (bottom) Spklp immunoprecipitation and immunoblot, at indicated times after galactose addition. ([-) Nonbudded cells; $(\uparrow)$ small budded cells; ( $U$ ) large budded cells. (C) Similar to the experiment in $B$.

apparent S-phase regulation of $S p k 1 p$ in $\operatorname{cln} 1 \Delta, \operatorname{cln} 2 \Delta$, cln3A, GAL1-CLN3 cells may have been induced or enhanced by using an atypical Cln3-driven cell cycle. A number of functional differences have been described between $C \ln 3$ and $C \ln 1$ and $C \ln 2$, although they are functionally redundant in passage through Start (Vallen and Cross 1995).

\section{Modification of Spk1p in cell cycle-arrested $\mathrm{cdc}^{t s}$ mutants}

We then used a set of temperature-sensitive cell division cycle $\left\langle c d c^{t s}\right)$ mutant strains under nonpermissive conditions to define more precisely the timing of the mobility shift. At $37^{\circ} \mathrm{C}, c d c 28$ (cyclin-dependent kinase) cells arrest at Start, whereas $c d c 34, c d c 4$, and $c d c 7$ strains arrest after Start but before the onset of DNA synthesis (Hereford and Hartwell 1974; Kolman et al. 1992; Smith et al. 1992; Sorger and Murray 1992). Cdc34p is a ubiquitinconjugating enzyme apparently required to activatc $G_{1} / S$ $\mathrm{Clb} / \mathrm{Cdc} 28$ complexes through destruction of the inhibitor Siclp (Schwob et al. 1994). CDC4 interacts genetically with $C D C 34$ (Smith et al. 1992). Cdc7 is a protein kinase with a terminal arrest point genetically downstream of the $c d c 4$ arrest point (Hereford and Hartwell
1974; Bahman ct al. 1988|. Spk1p migrated as a singlet in cdc28, cdc34-, and cdc4-arrested cells but was shifted partially in $c d c 7$-arrested cells (Fig. 2, lanes 0). Thus, Spklp begins to undergo modification near the $G_{1} / S$ boundary.

We then examined Spklp in cells arrested in S phase. $c d c 2$ (DNA polymerase $\delta$ ); $c d c 17$ [DNA polymerase $\alpha$ ), and $c d c 8$ (thymidylate kinase) strains arrest with stalled DNA replication (Sclafani and Fangman 1984; Lucchini et al. 1990; Budd and Campbell 1993). Consistent with results derived from the GAL-CLN3 arrest-release experiment (see Fig. 1B), Spklp underwent modification in $S$ phase-arrested $c d c$ mutants $(c d c 2, c d c 8$, and $c d c 17)$ (Fig. 3). Under these conditions, Spk1p was converted almost completely to the shifted form. We also used hydroxyurea (HU) as another method for accumulating cells arrested in $\mathrm{S}$ phase. HU inhibits ribonucleotide reductase, depleting deoxyribonucleotide pools so that cells accumulate at the S-phase checkpoint. Spklp shifts were induced by treatment of non-cdc strains with $\mathrm{HU}$ \{Fig. 2).

Spklp was also analyzed in $c d c$ mutants that arrest in $\mathrm{G}_{2}$ and $\mathrm{M}$. Mutants in $c d c 9$ (DNA ligase) and $c d c 13$ arrest in $\mathrm{G}_{2}$ (Tomkinson et al. 1992; Weber and Byers 1992). Spklp was converted to the shifted form in $c d c 9$ 

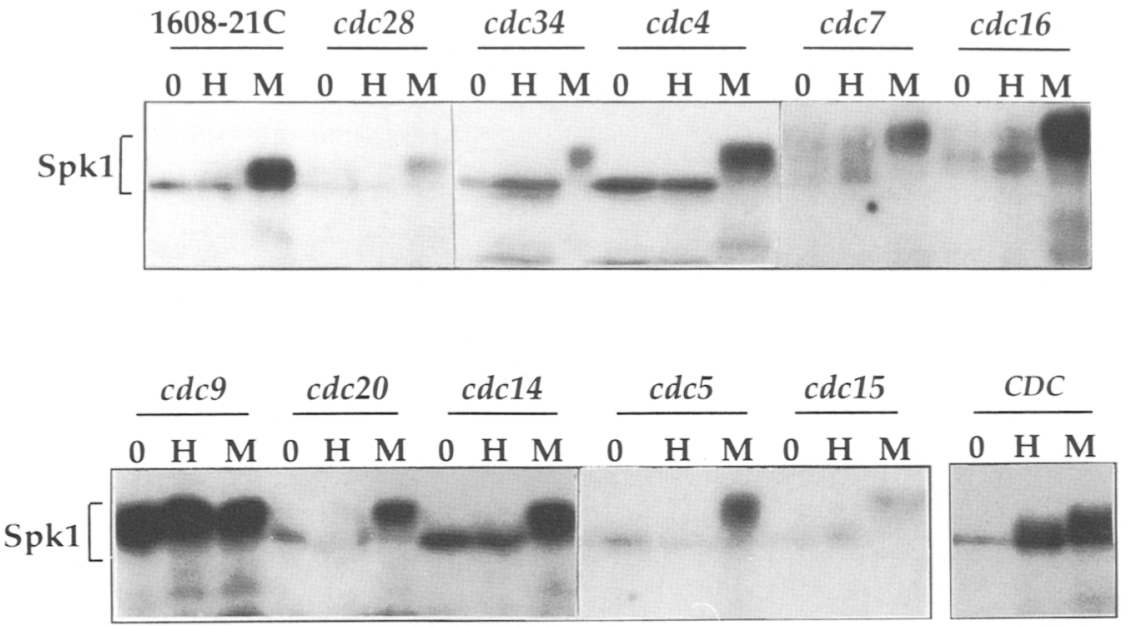

Figure 2. MMS- and HU-regulated Spklp modification in $c d c$ mutants. $c d c^{i s} \mathrm{mu}^{-}$ tants were arrested by incubation at the nonpermissive temperature $\left(37^{\circ} \mathrm{C}\right)$ for $4 \mathrm{hr}$. 1608-21C cells were arrested by incubation in YPD at $30^{\circ} \mathrm{C}$ for $4 \mathrm{hr}$. Cells were then incubated in YPD (lanes 0), YPD-100 mM HU (lanes $\mathrm{H}$ ), or YPD- $0.1 \%$ MMS (lanes $\mathrm{M}$ ) for an additional $4 \mathrm{hr}$ at $30^{\circ} \mathrm{C}$, or $37^{\circ} \mathrm{C}\left(c d c^{t s}\right)$, followed by immunoprecipitation and immunoblotting with antiSpklp. In this composite, $1608-21 \mathrm{C}$ and h28clal (cdc28) lanes were from a single gel; ZY35-34A (cdc34) and h4clal (cdc4) lanes were from a single gel $;$ h $7 \mathrm{c} 4 \mathrm{al}(\mathrm{cdc} 7)$ and h16clal $(c d c 16)$ samples were from a single gel; h9cla) (cdc9), 2593 (cdc20), 1082 (cdc14) samples were from a single gei; hclbl (cdc5) and 1081 (cdc15) samples were from a single gel; and Y203 (CDC) lanes were from a single gel. Indicated strains were arrested and incubated in YPD (lanes 0), in YPD-HU (lanes H), or YPD-MMS (lanes M), and Spklp was detected by immunoprecipitation/immunoblotting.

(Fig. 2, lane 0) and $c d c 13$ (Fig. 4A, lane $c d c 13 /+$ ) cells, whereas in cdc16 cells, arrested at the metaphase/ anaphase boundary, Spk1p was shifted only partially (Fig. 2, lane 0). Spk lp migrated as a singlet in all other $M$ phase-arrested $c d c$ mutants (Fig. 2, cdc20, cdc14, cdc5, cdc15, lanes 0).

\section{Phosphatase treatment of Spk1p}

To determine whether the mobility shift of Spklp results from phosphorylation, Spklp was immunoprecipitated from lysates of $c d c 8^{t s}$ cells arrested at the nonpermissive temperature and incubated with calf intestine alkaline phosphatase (CIP). Much of Spklp was converted to the basal mobility form (Fig. 5, cf. 20-min time point to Gal-Spk1 basal form). This conversion did not occur in the presence of $\beta$-glycerophosphate, a phosphatase inhibitor (Fig. 5). The remainder was converted to an intermediate form. Although it is likely that this component is partially CIP resistant for technical reasons (e.g., the precipitating antibody may block access to phosphorylation sites , it is possible that there is an additional modification (e.g., ubiquitination).

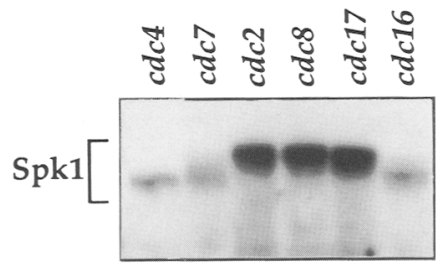

Figure 3. Spklp modification in $c d c^{t s}$ strains. h4clal, h7c4al, h2c2al, h8clal, h17clal, and h16clal (cdc4,cdc7,cdc2, cdc8, $c d c 17$, and $c d c 16$, respectively| strains as indicated were arrested by incubation at the nonpermissive temperature for $4 \mathrm{hr}$. Lysates werc immunoprecipitated and immunoblotted with anti-Spklp.
Trans-phosphorylation of $S p k 1 p$

The regulated phosphorylation of Spk $1 \mathrm{p}$ could arise from autophosphorylation or from phosphorylation by another protein kinase. To distinguish between these two possibilities, Spklp phosphorylation was analyzed in spk1 $1 \Delta$ strains expressing only kinase-defective versions of Spk 1p [spk1-1 (A208P), spk1 D339A, and spk1 K227A/ $D 339 A$ ] after treatment with HU. spk1-1 is a viable checkpoint allele that contains a single point mutation

A

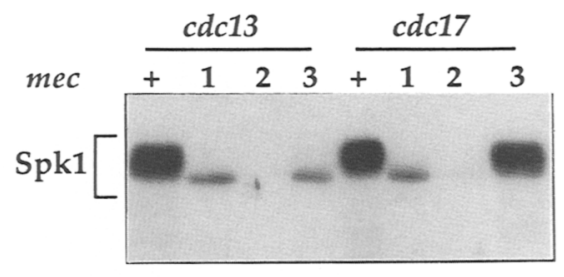

B

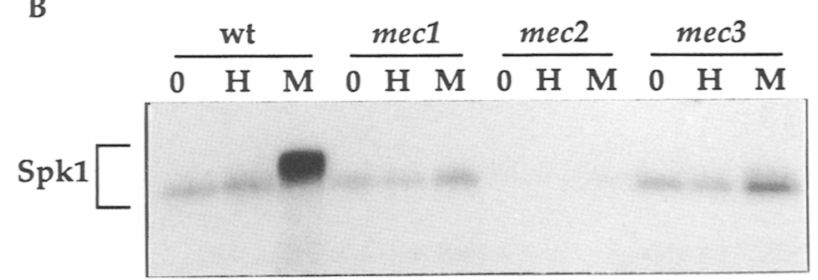

Figure 4. Regulation of Spklp in mec strains. (A) TWY146 (cdc13), TWY158 (cdc13 mec1), TWY148 (cdc13 mec2), TWY159 (cdc13 mec3), TWY446 (cdc17), TWY447 (cdc17 mec1), TWY448 (cdc17 mec2), and TWY449 (cdc17 mec3) cells wcre incubated at $37^{\circ} \mathrm{C}$, the nonpermissive temperature for $4 \mathrm{hr}$, and analyzed by anti-Spk lp immunoprecipitation and immunoblotting. (B) TWY397 (MEC), TWY308 (mec1), TWY312 (mec2), and TWY316 (mec3) cells were arrested by incubation in nocodazole for $150 \mathrm{~min}$ (Jacobs et al. 1988) and treated with 100 mM HU or $0.1 \%$ MMS for $2 \mathrm{hr}$. Lysates were immunoprecipitated and immunoblotted with anti-Spklp. 


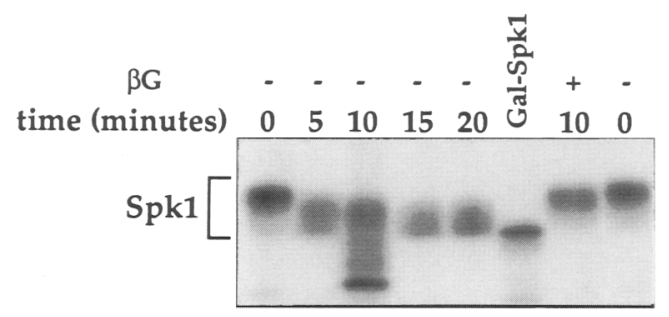

Figure 5. Phosphatase treatment of Spklp. Spklp was immunoprecipitated from lysates of h8clal (cdc8) cells arrested by incubation at the nonpermissive temperature for $4 \mathrm{hr}$. Immune complexes bound to protein A-Sepharose were incubated in 100 $\mu l$ HEPES buffer [20 mM HEPES-NaOH (pH 7.3), $20 \mathrm{~mm} \mathrm{MgCl}_{2,}$ $40 \mathrm{mM} \mathrm{KCl}, 0.2 \mathrm{~mm}$ PMSF] containing 100 units of CIP at $37^{\circ} \mathrm{C}$ for the indicated periods of time (Rice et al. 1994). Gal-Spkl is a marker for the nonshifted form. The low molecular weight material at the 10-min time point is smaller than the Spklp primary translation product and probably arose through proteolysis. $\beta$-Glycerophosphate $(5 \mathrm{~mm})$, an inhibitor of CIP, was included in the reaction marked. Shown is the time course of Spk lp incubation with CIP in the absence $(-)$ or presence $(+)$ of $\beta$-glycerophosphate $(\beta G)$.

(A208P) and has $\sim 10 \%$ of the catalytic activity of wildtype Spk1p (D.S. Fay and D.F. Stern, in prep.). [Although SPK1 is an essential gene, spk1A strains can be derived. These strains presumably harbor second-site suppressors, but their growth, checkpoint, and damage sensitivity phenotypes are all reverted by reintroduction of $S P K 1$ (Zheng et al. 1993; D.S. Fay and D.F. Stern, in prep.)). Both spk1 D339A and spk1 K227A/D339A mutants have substitutions at conserved residues within the catalytic domain of Spklp, have no biological activity, and are likely to be devoid of phosphotransferase activity (D.S. Fay and D.F. Stern, in prep.) All three kinase-defefctive proteins shifted to mobilities comparable to those of wild-type Spklp after treatment with $\mathrm{HU}$ (Fig. 6, lanes $\mathrm{H})$. Thus, HU induces Spklp phosphorylation in trans.

\section{DNA damage induces Spk1p phosphorylation} in a cell cycle-independent manner

Spklp is postulated to be an intermediary in a signal transduction cascade linking incompletely replicated or damaged DNA to cell cycle arrest (Zhou and Elledge 1993; Allen et al. 1994). If so, then induction of checkpoint arrest should activate Spk $1 p$ functionally. Hence, we sought to determine whether Spklp is regulated by phosphorylation during the damage response. After treatment of log-phase cultures with the alkylating agent methyl methanesulfonate (MMS), Spklp shifted to the low mobility form isee Fig. 2). There are at least two possible explanations for this result. One is that treatment with MMS leads to the accumulation of cells in cell cycle phases wherein Spklp is normally phosphorylated. An alternative is that exposure to MMS induces Spklp phosphorylation independently, through pathways associated with the DNA damage response. To distinguish between these two possibilities, $c d c^{t s}$ strains, prearrested in either $G_{1}$ or $M$ phases by temperature shift, were exposed to MMS or HU. Similarly, 1608-21C cells $(c \ln 1 \Delta, c \ln 2 \Delta, c \ln 3 \Delta, G A L-C L N 3)$ were prearrested in $\mathrm{G}_{1}$ by switching to glucose medium before treatment with MMS or HU. As discussed above, Spklp migrated either as a single band in untreated cells (1608-21C, $c d c 28, c d c 34, c d c 4, c d c 20, c d c 14, c d c 5$, and $c d c 15)$ or was shifted partially $(c d c 7)$ (see Fig. 2, lanes 0$)$. When these strains were treated with MMS, Spklp was converted to the shifted form (see Fig. 2, lanes $M$ ). This result demonstrates that the induction of Spklp phosphorylation in response to DNA damage is independent of position within the cell cycle and that none of these $C D C$ and $C L N$ genes are required for the induction of Spk1p phosphorylation. In contrast to MMS, HU did not affect Spk $1 p$ mobility in $G_{1}$ and $M$ phase-arrested cells (see Fig. 2, lanes H). This result is not surprising, as the effects of $\mathrm{HU}$, which depletes nucleotide precursors, may only be sensed in the face of ongoing replication.

Some checkpoint-defective mutants are defective in the induction of $S p k 1 p$ phosphorylation

The above results suggest a direct correlation between Spklp phosphorylation and the activation of checkpoint pathways. If Spklp phosphorylation is required for these pathways, it should be possible to identify checkpoint mutants that act upstream of Spklp by measuring the extent of Spklp phosphorylation in checkpoint-defective strains treated with agents that induce checkpoint arrest (MMS and HU). MEC1, MEC2/SPK1, and MEC3 were identified in a screen for mutants in the DNA damage checkpoint that is synthetically lethal with $c d c 13^{t s}$ (Weinert et al. 1994). MEC1 is related to human ATM (Savitsky et al. 1995), and MEC2 is allelic to SPK1. MEC1 and $M E C 2$ are both essential genes that are necessary for DNA damage-induced and $S$ phase checkpoint pathways, whereas $M E C 3$ is involved exclusively in DNA damageinduced checkpoint arrest (Weinert et al. 1994). $c d c 17^{t s}$ and $c d c 13^{\text {ts }}$ were uscd to activate replication and damage checkpoints, respectively, in $M E C^{+}, m e c 1, m e c 2$, and mec3 backgrounds (see Fig. 4A).

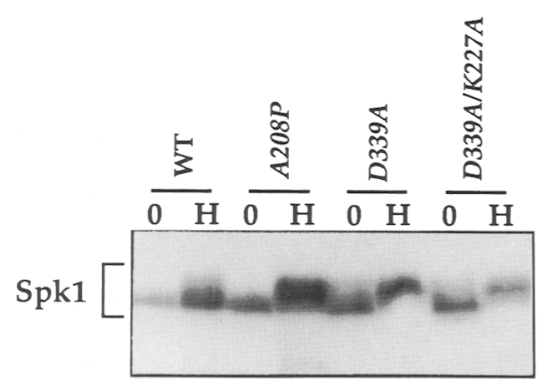

Figure 6. Phosphorylation of kinase-defective Spklp. DZ413 (spk1S) cells expressing wild type (WT) and kinase-defective spk1 mutants were incubated in YPD (lanes O) or YPD-HU (lanes $\mathrm{H}$ ) for $4 \mathrm{hr}$ at $30^{\circ} \mathrm{C}$. Spk1p was detected by immunoprecipitation and immunoblotting. 
Spklp was converted to the phosphorylated form after temperature shift in $c d c 13^{t s} M E C$ and $c d c 17^{t s} M E C$ cells (Fig. 4A, lanes $c d c 13 /+$ and $c d c 17 /+$ ). In contrast, Spk1p remained unshifted in $c d c 13^{t s}$ mec1 and $c d c 17^{t s}$ mec1 strains (Fig. 4A, lanes $c d c 13 / 1$ and $c d c 17 / 1$ ). Mobility shift of Spklp was observed in cdc17 mec3 cells but not in $c d c 13$ mec 3 cells.

To verify that the $M E C+1$-dependent shift of $S p k 1 p$ is not a result of cell cycle synchronization, we prearrested cells in $\mathrm{M}$ phase with nocodazole and then treated them with MMS (Fig. 4B). In nocodazole-arrested wild-type cells, Spklp shifted in response to MMS, whereas in mec1- and mec3- arrested cells, Spk1p remained at the unshifted position (Fig. 4B). These results placed Meclp upstream from Spklp in both damage- and replicationregulated pathways, and $M e c 3 p$ upstream from $S p k l p$ in the damage-rcgulated pathway where Mec3p functions.

Mec2-lp accumulated at low levels and remained at the singlet position in both $c d c 13^{t s}$ mec2 and $c d c 17^{t s}$ mec2 cells at the nonpermissive temperature (Fig. 4A, lane $c d c 17 / 2$ (for $c d c 13, \mathrm{Z}$. Sun, unpubl.) and in nocodazole-arrested cells treated with MMS (Fig. 4B). Hence, the mec2-1 defect may prevent interaction with upstream regulators. Both the failure of Mec2-1p to undergo phosphorylation in response to either DNA damage or DNA replication blocks and the low protein levels may account for the checkpoint defect of mec2-1 strains.

\section{Kinase activity of $S p k 1 p$ increases with phosphorylation}

The results described above demonstrate that $S p k 1 p$ phosphorylation is regulatcd during cell cycle progression and in response to DNA damage or blocks to DNA replication, and suggest that this phosphorylation links upstream regulation of damage-response pathways to Spklp. If this phosphorylation is significant, it would be expected to regulate Spklp function. Therefore, we compared the kinase activities of shifted and basal forms of Spklp. We used an exogenous substrate (histone $\mathrm{H} 1$ ) in immune complex kinase assays to eliminate uncertainties regarding basal occupancy of Spk $1 \mathrm{p}$ autophosphorylation sites. GAL1-SPK1-overexpressed Spk1p was immunoprecipitated from cells treated with $\mathrm{HU}$, and immune complexes were incubated with $\left[\gamma^{-}{ }^{32} \mathrm{P} \mid \mathrm{ATP}\right.$ and histone $\mathrm{Hl}$. The intensities of histone phosphorylation relative to Spk lp levels (determined by immunoblotting) were normalized after quantification by PhosphorImager analysis. A representative experiment is shown in Figure 7. Histone $\mathrm{Hl}$ kinase activity was not associated with the kinase-impaired mutant Spk1-1p (Fig. 7), verifying that the assay measures Spklp activity and not that of a contaminating $\mathrm{Hl}$ kinase. ( $\mathrm{H} 1$ kinase activity was not recovered with immunc complexes from HU-treated spk1-1 cells either, data not shown.) In data from seven independent trials, the $\mathrm{Hl}$ kinase activity of $\mathrm{Spk} 1 \mathrm{p}$ from HU-treated cells normalized to Spklp protein level was 2.4 times that of unshifted Spk $1 \mathrm{p}$ (standard error $=0.5$ ). A two-tail $t$-test verified that this difference is statistically significant $(P<0.05)$. Thus, Spk1p catalytic activity is in-
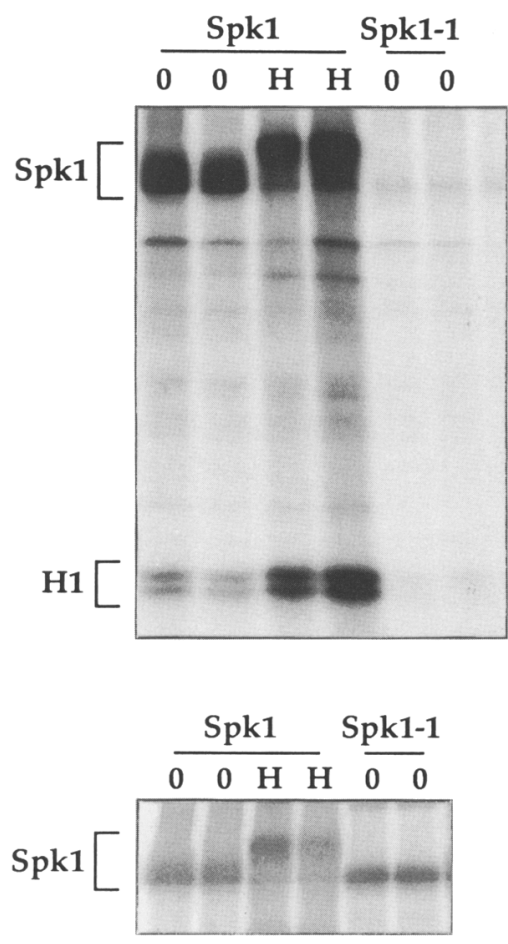

Figure 7. Kinase activity of shifted Spk1p. NY605 SPK1 or NY605 spk1-1 cells were incubated in YPG for $3 \mathrm{hr}$ at $30^{\circ} \mathrm{C}$, harvested (lanes 0), or followed by additional overnight incubation in YPG-100 mM HU (lanes H). Anti-Spklp immunoprecipitates were prepared and apportioned for parallel assay of histone $\mathrm{Hl}$ kinase activity (top) and for Spklp protein level (by immunoblotting (bottom) as described in Materials and methods. Phosphorylated histone $\mathrm{H} 1$ and immunoreactive Spklp idetected with ${ }^{125}$ I-labeled protein A) were quantified using a General Dynamics PhosphorImager. Data shown are representative of seven similar experiments that were subjected to statistical analysis as discussed in the text. Anti-Spklp immune complexes containing Spklp or Spkl-1p (as marked) were divided and incubated with $\left[\gamma^{32} \mathrm{P} \mid \mathrm{ATP}\right.$ in the presence of histone H1 |top| or immunoblotted with anti-Spklp (bottom|. Samples were prepared from mock-treated (lanes 0 ) or HU-treated cells (lanes H).

creased modestly after exposure of $\mathrm{Spk} 1 \mathrm{p}$ to agents that induce checkpoint arrest.

\section{Overexpression of Spk1p leads to cell cycle delay}

If $S p k 1 p$ is a member of a pathway connecting DNA damage to checkpoint arrest, then functional activation of Spklp should be sufficient to induce arrest. To test this possibility, cells carrying galactose-inducible SPK1 and checkpoint-defective spk1 kinase mutants (Zheng et al. 1993; D.S. Fay and D.F. Stern, in prep.) were arrested with $\alpha$ factor and induced with galactose. After release from Start arrest, cells were analyzed by flow microfluorimetry. Cells overexpressing spk1-1, spk1 K227A, and empty vector entered $S$ phase after $45 \mathrm{~min}$, coordinate with appearance of budded cells (Fig. 8). However, overexpression of wild-type Spk1p delayed DNA synthesis 
A

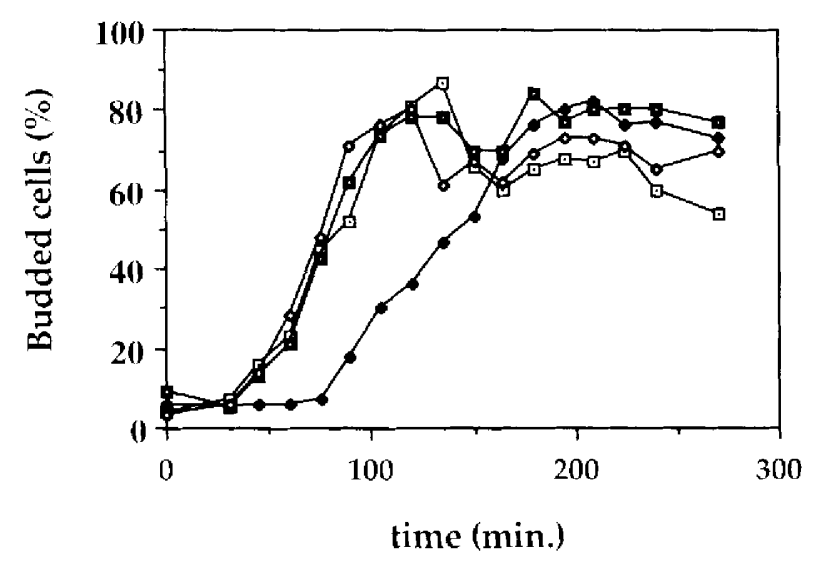

C pNB187-SPK1

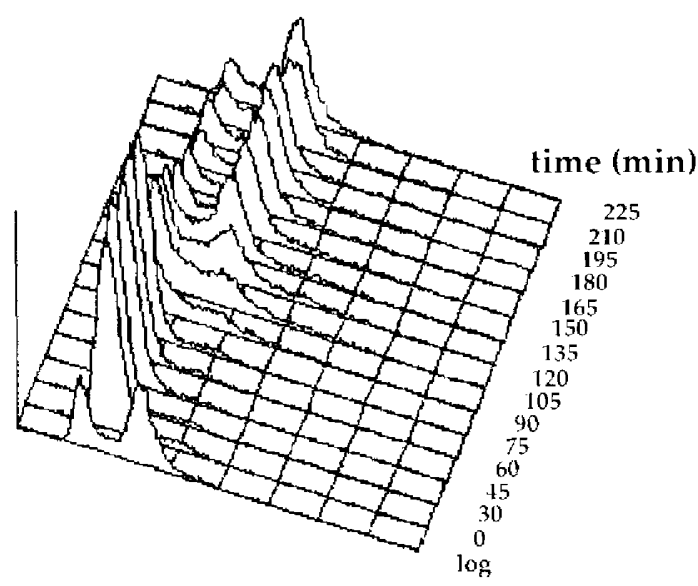

Figure 8. Overexpression of $S P K 1$ causes cell cycle delays. Plasmids pNB 187 (口), pNB 187-SPK1 ( I. pNB 187-spk1-1 [C), and pNB 187-spk1-K227A 0 ) were introduced into strain K699. Strains were grown in $2 \%$ raffinose and synchronized by $\alpha$-factor treatment as described previously (Pizzagalli et al. 1992). Cells were grown to early log phase, and the medium was adjusted to 10 mM sodium citrate $(\mathrm{pH} 4 \mid, 200 \mu \mathrm{g} / \mathrm{ml}$ bovine serum albumin, and $2 \mu \mathrm{g} / \mathrm{ml} \alpha$-factor (Sigma). $\alpha$-Factor was removed from the culture by filtration and washing when the proportion of unbudded cclls was $-95 \%$. At the time of $\alpha$-factor release, $2 \%$ galactose was added. FACS was performed as described previously (Foiani et al. 1994). At the time of $\alpha$-factor release, $2 \%$ galactose was added. Fixation, propidium-iodide staining, and flow microfluorimetry analysis were performed as previously described (Foiani et al. 1995). (A) Percentage budded cells as a function of time after mating factor release. $(B-E)$ Flow analysis of log-phase cells and mating factor-synchronized cells as a function of time after mating factor washout.

and budding until 90 min (Fig. 8, GAL1-SPK1). Thus, Spklp overexpression delays the $G_{1} / S$ transition (or pre-

\section{B pNB187}

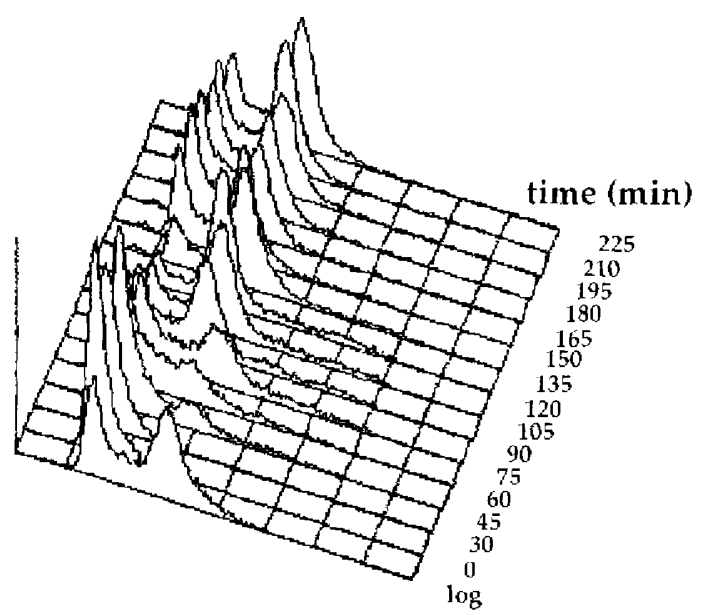

D pNB 187-spk1-1

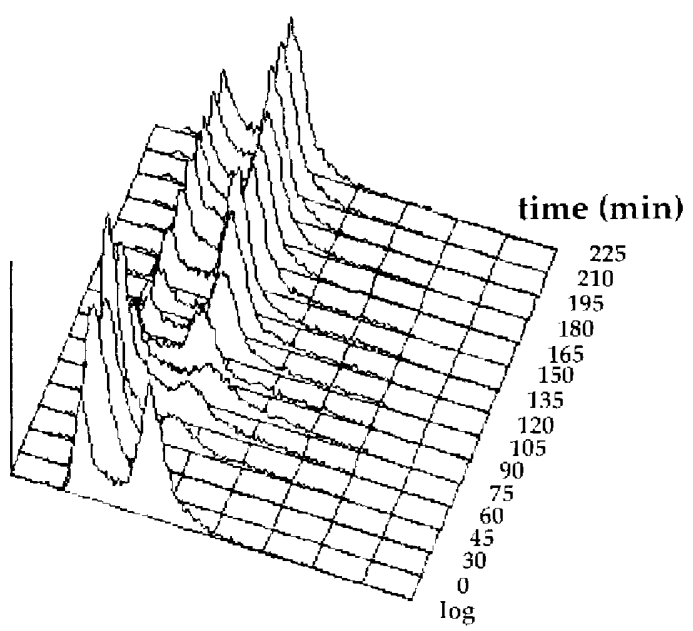

E pNB 187-spk1-K227A

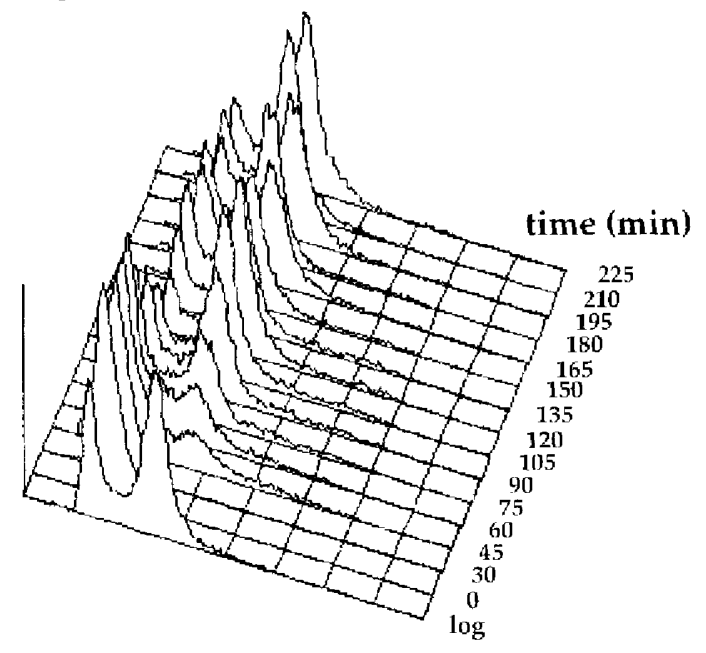

vents substantial replication from occurring within S). The inability of checkpoint-defective mutants to induce 
the delay suggests that overexpressed Spk $1 p$ acts directly on checkpoint-specific targets.

\section{Discussion}

Spk1p is a common signal transducer in multiple checkpoint pathways

Previous evidence suggested that Spklp is a node for integration and transmission of the damage and replication checkpoint signals. This model predicts that $|1| \mathrm{Spk} 1 \mathrm{p}$ is required for these pathways; (2) intrinsic and extrinsic activation of these pathways should regulate Spk1p; (3) Spklp regulation should be associated with altered Spklp function; and (4) artificial activation of Spk1p should induce checkpoint arrest. With the present data, these criteria have now been met: (1) spk1 mutants are checkpoint defective; (2) Spk1p phosphorylation is increased by inducers of damage and replication checkpoints; (3) Spklp phosphorylation correlates with increased kinase activity; and (4) overexpression of Spklp, but not a checkpoint mutant, induces cell cycle delay.

\section{Checkpoint regulation of $\operatorname{Spk} 1 p$}

Spklp was mobility-shifted in $c d c 9$ and $c d c 13$ cells, MMS-treated, and HU-treated cells. Thus, conditions that activate DNA damage-dependent checkpoint pathways, as wcll as the $S$ phase $(H U)$ checkpoint pathway, also up-regulate Spklp phosphorylation. Phosphorylation of Spklp after treatment with HU moderately increased the in vitro kinase activity of Spklp. Use of a more physiological substrate (once identified) or soluble enzyme rather than immune complexes might reveal a more profound catalytic regulation. Although it is possible that other phosphorylation-regulated processes [localization, stability, or binding to other proteins) are important for checkpoint functions, our finding that a kinase domain mutation that weakens, but does not ablate, Spklp catalytic activity leads to checkpoint defects suggests that catalytic regulation of $S p k l p$ is a limiting component of Spklp signaling (D.S. Fay and D.F. Stern, in prep.).

\section{MECl and MEC3 may act upstream of SPK 1}

In an cffort to define further the signaling cascade leading to checkpoint activation, we examined cells containing checkpoint-defective alleles of $M E C 1$ and $M E C 3$ for the ability to shift Spklp in response to DNA damage and blocks to DNA replication. Spklp remained in the basally phosphorylated state after temperature shift of both mec1cdc1 $3^{\text {ts }}$ and mec3cdc13 $3^{\text {ts }}$ cells and MMS treatment of nocodazole-arrested mec1 and mec 3 cells. These results suggest that $M E C 1$ and $M E C 3$ lie upstream in the pathway leading to checkpoint arrest after DNA damage (Fig. 9). It should be noted, however, that MMS treatment and $c d c 13$ arrest generate different lesions and may exert different effects on checkpoint pathways. Spklp was unshifted in mec1cdc1 $7^{\text {ts }}$ strains at the nonpermis-

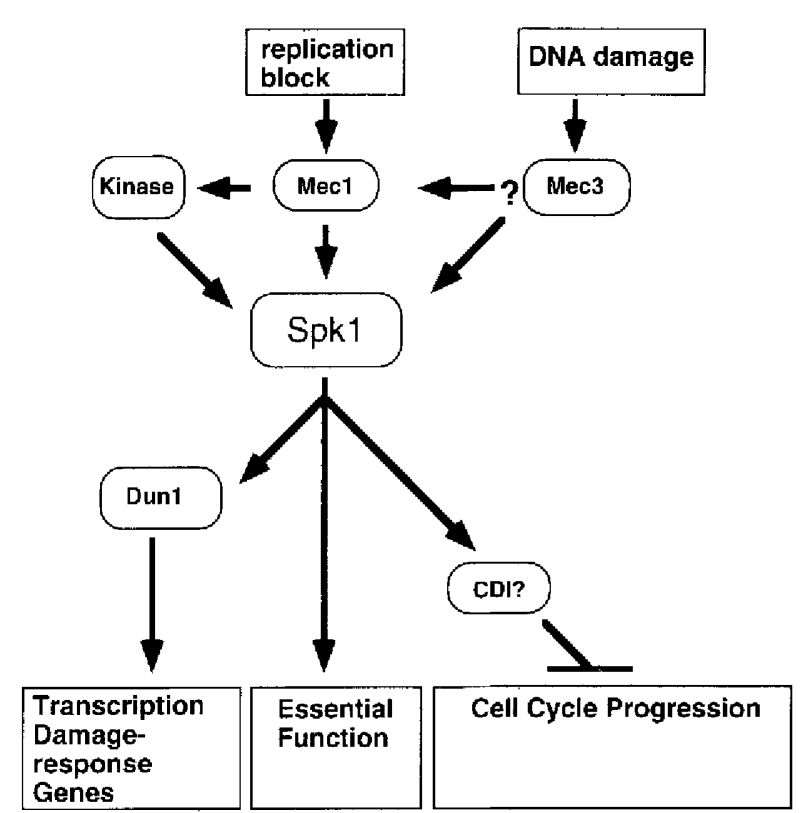

Figure 9. Model for SPKI function. Spklp is regulated by inhibition of replication, by DNA damage, and probably by an S-phase function during normal growth. $M E C 1$ and $M E C 3$ are required for Spk 1 p phosphorylation and for operation of damage \{MEC3) or damage pius replication [MEC1) checkpoints. Mecl is a likely candidate for the kinase that phosphorylates Spklp. $S P K 1$ is required for an essential function (probably linked to replication), for induction of certain DNA damage-induced transcripts (requires DUN1), and for checkpoint arrest $\{D U N 1$ independent). See text for further details.

sive temperature but was shifted in mec3cdc1 $7^{t s}$ cells. Because MEC3 is not required for activation of the S-phase checkpoint, it appears that $M E C 3$ acts upstream of SPK1 only in the DNA damage-induced checkpoint pathway, whereas $M E C 1$ functions upstream in both pathways. The phosphorylation data establish a strong correlation of Spklp mobility shift with the functional activation of these two checkpoint pathways and provide direct biochemical evidence corroborating the hypothesis that multiple checkpoint pathways converge on Spklp.

\section{Spk1p in a protein kinase cascade}

Spklp functions within a protein kinase cascade because kinase-defective Spklp shows HU-dependent phosphorylation and because Spklp phosphorylation correlates with Spklp activity. This cascade may extend one level deeper, as the protein kinase Dun $l p$ itself requires SPKI for damage-regulated phosphorylation (Zhou and Elledge 1993|. The strongest candidates for protein kinases that regulate Spklp directly are Meclp and Tellp. Structurally, they belong to a subgroup of the lipid kinase family including Schizosaccharomyces pombe rad3, Drosophila melanogaster mei-41, mammalian $A T M$, and DNA-protein kinase catalytic subunit (DNA-PK $\mathrm{Cs}$ ) (AlKhodairy and Carr 1992; Hari et al. 1995; Morrow et al. 
1995; Savitsky et al. 1995]. Of these, only DNA-PK has been tested for catalytic activity, and it is a protein kinase with no detectable lipid kinase activity (Hartley et al. 1995). Currently, it is not known whether Mecl can act as a protein kinase or whether the catalytic activity of $\mathrm{Mecl}$ is stimulated by DNA damage. Nevertheless, it is logical to suppose that Spklp not only interacts directly with Meclp but that Meclp and its relative Tellp are the protein kinases that regulate Spklp. Intriguingly, Spklp contains multiple consensus sites for phosphorylation by DNA-PK (Hartley et al. 1995). The other obvious candidates, $\mathrm{Cdc} 28 \mathrm{p}$ and $\mathrm{Cdc} 7 \mathrm{p}$, cannot be required exclusively, as MMS regulates Spklp phosphorylation in $c d c 28$ - and $c d c 7-$ arrested cells (Fig. 2). However, it is quite possible that multiple protein kinases act on Spklp.

\section{DNA replication and checkpoint controls}

In contrast to other checkpoint control genes, Meclp and Spklp share the property of being essential for viability. Little is known about the essential functions of these proteins, but based on circumstantial evidence /coregulation with DNA synthetic enzymes, terminal arrest phenotype, nuclear localization| we have hypothesized that the essential function of $S p k 1 p$ is associated with DNA replication (Zheng et al. 1993). The $c \ln 1 \Delta, c \ln 2 \Delta$, $\operatorname{cln} 3 \Delta$, GAL1-CLN3 experiment may indicate that Spklp is modified post-translationally in S-phase cells and that this modification parallels activation through the induction of checkpoint pathways. Three models might explain such a function. The most likely model is that Spk1p has dual functions: to regulate replication positively and to regulate cell cycle progression negatively. For example, it would be advantageous for damage-dependent checkpoint pathways to coordinately inhibit cell cycle progression and activate DNA replication and repair enzymes, which could be accomplished through phosphorylation of different proteins by Spk1p. A similar function in $\mathrm{S}$ phase would link activation of normal DNA replication to inhibition of progression out of S-phase. This model predicts that replication and checkpoint functions are separable, that checkpoint functions are dispensable for viability, and that Spklp normally functions in S phase. Although these predictions are met, there is no direct evidence regarding a requirement of $\mathrm{Spk} 1 \mathrm{p}$ for replication. In a variant of this model, the checkpoint functions are secondary to induction of "replication structures" by Spk1p. Such structures could themselves be the signal recognized by the checkpoint apparatus. A problem with this model is that it does not fit well with the damage checkpoint function, as it would require a second, independent mechanism to identify DNA damage outside of S phase. (Such a mechanism could involve an analogous "transcription structure" created by processing RNA polymerase complexes.) A final model is that the chronic function of Spklp is a checkpoint function, that, for example, curtails $G_{2}$ activities during $S$ phase. This is consistent with the checkpoint function of Spklp, and with S-phase phosphorylation. Thus $c d c 18$ and cut 5 of fission yeast have been proposed to play a role in both the initiation of DNA replication and the restraint of mitosis (Kelly et al. 1993; Saka and Yanagida 1993|. However, this model is difficult to reconcile with the viability and robust growth of checkpoint mutants.

\section{Conservation of checkpoint pathways}

The pathways regulating the response to DNA damage seem to be conserved among all eukaryotes. A fission yeast gene, $c d s 1^{+}$, has considerable structural homology to the amino-terminal and catalytic domains of Spklp. $c d s 1^{+}$may be required for activation of the $S$ phase but not for the DNA damage-regulated checkpoint (Murakami and Okayama 1995). Similarly, rad3 ${ }^{+}$is similar to $M E C 1$ and may operate upstream of $c d s 1^{+}$, as $c d s 1^{+}$ overexpression suppresses rad3-HU sensitivity (Murakami and Okayama 1995). Thus, fission yeast genes and the $S P K 1$ homolog $c d s 1^{+}$are both structurally and functionally similar to $M E C 1$ and SPK1 and are both necessary for the HU-sensitive checkpoint (Al-Khodairy and Carr 1992; Murakami and Okayama 1995). The further structural and functional conservation of Mecl-related genes in humans and the vast genetic distance between $S$. cerevisiae and $S$. pombe make it likely that a human homolog of SPK1 exists. An increasing number of human tumor suppressor genes have functions connected directly to the DNA damage-response network. The conservation of these pathways in all eukaryotes means that further elucidation of the $\mathrm{Mec} 1 \mathrm{p} / \mathrm{Spk} \mathrm{lp}$ pathway in budding yeast is certain to further our understanding of the role that checkpoint genes play in human cancer.

\section{Materials and methods}

\section{Immunoprecipitation of $\operatorname{Spk} 1 p$}

Immunoprecipitations were carried out in antibody excess as determined by titration. For Figures $1 \mathrm{~A}$ and B, 2, 3, 4B and C, 5, and 6 , cells from $500 \mathrm{ml}$ of culture per sample were collected by centrifugation and suspended in $2 \mathrm{ml}$ of glass bead disruption buffer [20 mM Tris-HCl $\mid \mathrm{pH} 7.9), 10 \mathrm{mM} \mathrm{MgCl}_{2}, 1 \mathrm{~mm}$ EDTA, $5 \%$ glyccrol, $0.3 \mathrm{M}$ ammonium sulfate, with freshly added $1 \mathrm{~mm}$ dithiothreitol, $1 \mathrm{~mm}$ phenylmethylsulfonyl fluoride, $1 \times$ protease inhibitor mix (Ausubel et al. 1991), $1 \mathrm{~mm}$ sodium orthovanadate, and $100 \mu \mathrm{M}$ sodium orthovanadate]. Samples were vortexed five times for $45 \mathrm{sec}$ in the presence of glass beads interspersed with cooling on ice for 1-2 min. Two milliliters of $\mathrm{TG}_{-}-\mathrm{VO}_{4}$ solution $\mid 1 \%$ Triton X-100, $10 \%$ glycerol, 0.198 trypsin inhibitor units (TIU) of aprotinin per milliliter of Dulbecco's phosphate-buffered saline lacking divalent cations with fresh $100 \mu \mathrm{M}$ sodium orthovanadate] was added, and samples were vortexed for an additional minute. Samples were cleared by centrifugation at $2500 \mathrm{rpm}$ for $10 \mathrm{~min}$ at $4^{\circ} \mathrm{C}$ in an IEC DPR-6000 centrifuge. Supernatants were transferred, diluted with $40 \mathrm{ml}$ of denaturation solution [ $10 \mathrm{mM}$ Tris- $\mathrm{HCl}(\mathrm{pH} 7.5$ ], SDS $0.5 \%$ ], heated to $100^{\circ} \mathrm{C}$ for $10 \mathrm{~min}$, and cooled on ice. Triton X-100 was added to $1.0 \%, 100 \mu$ l of rabbit anti-Spklp serum (Zheng et al. 1993) was added, and incubation was carried out at $4^{\circ} \mathrm{C}$ overnight with shaking. One hundred microliters of protein 
A-Sepharose [50\% suspension in PBS without divalent cations) was added, and incubations were continued for $3 \mathrm{hr}$ at $4^{\circ} \mathrm{C}$ with shaking. Beads were collected by centrifugation, transferred to $1.5-\mathrm{ml}$ Eppendorf tubes, and washed three times in $0.5 \mathrm{ml}$ of $\mathrm{TG}-\mathrm{VO}_{4}$ buffer. For Figure $4 \mathrm{~A}$, immunoprecipitation was carried out as described for the immunoprecipitation step in histone $\mathrm{Hl}$ kinase assays.

\section{Immunoblotting}

Samples were heated to $100^{\circ} \mathrm{C}$ for $5 \mathrm{~min}$ in $1 \times$ SDS sample buffer and fractionated on a $10 \%$ acrylamide- $0.13 \%$ bisacrylamide gel. Proteins were transferred to nitrocellulose (Bio-Rad) in transfer buffer 172.25 grams of glycine, 15 grams of Tris base, 3.75 grams of SDS, 0.46 grams of sodium orthovanadate, 1 liter of methanol, $\mathrm{H}_{2} \mathrm{O}$ to 4 liters! at $4^{\circ} \mathrm{C}$ for $1 \mathrm{hr}$ and $45 \mathrm{~min}$ at 500 $\mathrm{mA}$. Filters were then blocked in Blotto $15 \%$ Carnation Instant Milk in rinsing buffer (RB: $10 \mathrm{~mm}$ Tris- $\mathrm{HCl}$ at $\mathrm{pH} 7.4,0.9 \%$ $\mathrm{NaCl}, 0.01 \%$ sodium azide) overnight. Anti-Spklp antibody (1: 100 in Blotto was incubated with the filter for $2 \mathrm{hr}$ at room temperature with shaking followed by two 10-min washes in $\mathrm{RB}$, one 10 -min wash in RB containing $0.05 \%$ Triton $\mathrm{X}-100$, and two 10-min washes in RB. The filter was then incubated with ${ }^{125}$ I-labeled protein A in RB/Blotto $(30 \mu \mathrm{Ci}$ in $30 \mathrm{ml})$ for $30 \mathrm{~min}$ at room temperature with shaking and washed five times as above. Filters were autoradiographed for 2 days using preflashed film at $-70^{\circ} \mathrm{C}$.

\section{Histone H1 kinase assay}

NY605 SPK1 cells were grown overnight in synthetic complete medium lacking uracil $\mid \mathrm{SC}$-Ura|, diluted, and grown to $\log$ phase in YPR. $S P K 1$ overexprcssion was induced by addition of galactose to a final concentration of $2 \%$ (wt/vol). Three hours later, $100 \mathrm{~mm} \mathrm{HU}$ was added and cells were incubated at $30^{\circ} \mathrm{C}$ overnight. For HU-untreated cells, galactose was added on day 2 to a fresh log-phase culture of NY605 SPK1 and NY605 spk1-1 cclls Igrown as described as abovel. Cells were incubated for $3 \mathrm{hr}$ and harvested in parallel with HU-treated cells. One hundred fifty milliliters of cells was collected for each sample.

Cells were lysed in $0.5 \mathrm{ml}$ of glass bead disruption buffer by vortexing (as above), diluted with $0.5 \mathrm{ml}$ of $\mathrm{TG}-\mathrm{VO}_{4}$, and $80 \mu \mathrm{l}$ of anti-Spklp serum was added. After incubation for $1.5 \mathrm{hr}$ at $4^{\circ} \mathrm{C}$, each lysate was divided into four equal parts. Fifty microliters of protein $\mathrm{A}$-Sepharose (50\% in $\mathrm{TG}_{-} \mathrm{VO}_{4}$ solution) was added to each portion followed by a further incubation with rotation for $30 \mathrm{~min}$ at $4^{\circ} \mathrm{C}$. Sepharose beads were collectcd by centrifugation and were washed twice with $\mathrm{TC}_{-}-\mathrm{VO}_{4}$ solution and twice with kinase buffer $[20 \mathrm{~mm}$ HEPES (pH 7.4), $10 \mathrm{~mm}$ $\mathrm{MgCl}_{2}, 10 \mathrm{mM} \mathrm{MnCl}$ ]. Duplicate portions from each treatment were boiled immediately in $2 \times$ sample buffer for Western blot analysis. The other two were used for kinase assays. The washed complexes were incubated with $20 \mu \mathrm{Ci}$ of $\left[\gamma^{-32} \mathrm{P}\right] \mathrm{ATP}$ (Amersham; sp. act. $>5000 \mathrm{Ci} /$ mmole), $2 \mu \mathrm{g}$ of histone $\mathrm{H} 1$ (Sigma), and $1 \mu \mathrm{M}$ cold ATP in $25 \mu \mathrm{l}$ of kinase buffer for $7 \mathrm{~min}$ on ice. Reactions were terminated with $25 \mu \mathrm{l}$ of $2 \times$ sample buffer and boiling for $5 \mathrm{~min}$. The eluted proteins were analyzed by SDS PAGE. The intensities of phosphorylated histone $\mathrm{H} 1$ (kinase assays) and Spklp (immunoblots) were determined by PhosphorImager analysis.

\section{Acknowledgments}

We are grateful to Mike Snyder for several helpful discussions. We thank Dave Riese II, Mark Solomon, and David Gonda for evaluating the manuscript, and Fred Cross, Steve Elledge and Ted Weinert for providing strains. This work was supported by grant VM-70 to D.F.S. from the American Cancer Society (Z.S., D.S.F., and D.F.S.) and by Progetto Bilaterale 95.00840.CT04 from Centro Nazionale Ricerche Italy to M.F.

The publication costs of this article were defrayed in part by payment of page charges. This article must therefore be hereby marked "advertisement" in accordance with 18 USC section 1734 solely to indicate this fact.

\section{References}

Al-Khodairy, F. and A.M. Carr. 1992. DNA repair mutants defining G2 checkpoint pathways in Schizosaccharomyces pombe. EMBO I. 11: 1343-1350.

Allen, J.B., Z. Zhou, W. Siede, E.C. Friedberg, and S.J. Elledge. 1994. The SAD1/RAD53 protein kinase controls multiple checkpoints and DNA damage-induced transcription in yeast. Genes \& Dev. 8: 2416-2428.

Ausubel, F.M., R. Brent, R.E. Kingston, D.D. Moore, J.G. Seidman, J.A. Smith, and K. Struhl. 1991. Current protocols in molecular biology (ed. F.M. Ausubel, R. Brent, R.E. Kingston, D.D. Moore, J.A. Smith, J.G. Seidman, and K. Struhl), pp. 13.13. Wiley Interscience, New York.

Bahman, M., V. Buck, A. White, and J. Rosamond. 1988. Characterisation of the CDC7 gene product of Saccharomyces cerevisiae as a protein kinase needed for the initiation of mitotic DNA synthesis. Biochim. Biophys. Acta 951: $335-$ 343.

Budd, M.E. and J.L. Campbell. 1993. DNA polymerase $\delta$ and $\epsilon$ are required for chromosomal replication in Saccharomyces cerevisiae. Mol. Cell. Biol. 13: 496-505.

Foiani, M., F. Marini, D. Camba, G. Lucchini, and P. Plevani. 1994. The B subunit of the DNA polymerase $\alpha$-primase complex in Saccharomyces cerevisiae executes an essential function at the initial stage of DNA replication. Mol. Cell. Biol. 14: 923-933.

Foiani, M., G. Liberi, G. Lucchini, and P. Plevani. 1995. Cell cycle-dependent phosphorylation and dephosphorylation of the ycast DNA polymerase $\alpha$-primase B subunit. Mol. Cell. Biol. 15: 883-891.

Greenwell, P.W., S.L. Kronmal, S.E. Porter, J. Gassenhuber, B. Obermaier, and T.D. Petes. 1995. TELl, a gene involved in controlling telomere length in $S$. cerevisiae, is homologous to the human Ataxia Telangiectasia gene. Cell 82: 823-829.

Hari, K.L., A. Santerre, J.J. Sekelsky, K.S. Mckim, J.B. Boyd, and R.S. Hawley. 1995. The mei-41 gene of D. melanogaster is a structural and functional homolog of the human Ataxia Telangiectasia gene Cell 82: 815-821.

Hartley, K.O., D. Gell, G.C.M. Smith, H. Zhang, N. Divecha, M.A. Connelly, A. Admon, S.P. Lees-Miller, C.W. Anderson, and S.P. Jackson. 1995. DNA-dependent protein kinase catalytic subunit: A relative of phosphatidylinositol 3-kinase and the Ataxia Telangiectasia gene product. Cell 82: 849856.

Hartwell, L.H. and M.B. Kastan. 1994. Cell cycle control and cancer. Science 266: 1821-1827.

Hartwcll, L.H. and T.A. Weinert. 1989. Checkpoints: Controls that cnsure the order of cell cycle events. Science 246: 629634.

Hereford, L.M. and L.H. Hartwell. 1974. Sequential gene function in the initiation of Saccharomyces cerevisiae DNA synthesis I. Mol. Biol. 84: 445-461.

Jacobs, C.W., A.E. M. Adams, P.J. Szaniszlo, and J.R. Pringle. 1988. Functions of microtubules in the Saccharomyces cer- 
evisiae cell cycle. I. Cell Biol. 107; 1409-1426.

Kastan, M.B., Q. Zhan, W.S. El-Deiry, F. Carrier, T. Jacks, W.V. Walsh, B.S. Plunkett, B. Vogelstein, and J.A.J. Fornace. 1992. A mammalian cell cycle checkpoint pathway utilizing p53 and GADD45 is defective in Ataxia-Telangiectasia. Cell 71: 587-597.

Kato, R. and H. Ogawa. 1994. An essential gene, ESR1, is required for mitotic cell growth, DNA repair, and meiotic recombination in Saccharomyces cerevisiae. Nucleic Acids Res. 22: 3104-3112.

Kelly, T.J., G.S. Martin, S.L. Forsburg, R.J. Stephen, A. Russo, and P. Nurse. 1993. The fission yeast cde18 genc product couples $S$ phase to START and mitosis. Cell 74:371-382.

Kolman, C.T., J. Toth, and D.K. Gonda. 1992. Identification of a portable determinant of cell cycle function within the carboxyl-terminal domain of the yeast CDC34 (UBC3) ubiquitin conjugating (E2) enzyme. EMBO I. 11: 3081-3090.

Lambertus, J.W.M.O. and F.R. Cross. 1994. Gl cyclins CLN1 and CLN2 repress the mating factor response pathway at Start in the yeast cell cycle. Genes \& Dev. 8: 1058-1070.

Lane, D.P. 1992. p53, guardian of the genome. Nature 358: 1516.

Lehmann, A.R. and A.M. Carr. 1995. The ataxia-telangiectasia gene: A link between checkpoint controls, neurodegeneration and cancer. Trends Genet. 11: 375-377.

Lucchini, G., M.M. Falconi, A. Pizzagalli, A. Aguilera, H.L. Klein, and P. Plevani. 1990. Nucleotide sequence and characterization of temperature-sensitive pol1 mutants of Saccharomyces cerevisiae. Gene 90: 99-104.

Mcintosh, E.M. 1993. MCB elements and the regulation of DNA replication genes in yeast. Curr. Genet. 24: 185-192.

Meyn, M.S. 1995. Ataxia-telangiectasia and cellular responses to DNA damage. Cancer Res. 55: 5991-6001

Morrow, D.M., D.A. Tagle, Y. Shiloh, F.S. Collins, and P. Hieter. 1995. TEL1, an $S$. cerevisiae homolog of the human gene mutated in ataxia telangiectasia, is functionally related to the yeast checkpoint gene MEC1. Cell 82: 831-840.

Murakami, H. and H. Okayama. 1995. A kinase from fission yeast responsible for blocking mitosis in $\mathrm{S}$ phase. Nature 374: 817-819.

Murray, A. 1992. Creative blocks: Cell cycle checkpoints and feedback controls. Nature 359: 599-604.

Navas, T.A., Z. Zhou, and S.J. Elledge. 1995. DNA polymerase $\epsilon$ links the DNA replication machinery to the $S$ phase checkpoint. Cell 80: 29-39.

Paulovich, A.G. and L.H. Hartwell. 1995. A checkpoint regulates the rate of progression through $S$ phase in $S$. cerevisiae in response to DNA damage. Cell 82: 841-847.

Pizzagalli, A., S. Piatti, D. Derossi, I. Gander, P. Plevani, and G. Lucchini. 1992. Positive cis-acting regulatory sequences mediate proper control of POL1 transcription in Saccharomyces cerevisiae. Curr. Genet. 21: 183-189.

Rice, S.A., M.C. Long, V. Lam, and C.A. Spencer. 1994. RNA polymerase II is aberrantly phosphorylated and localized to viral replication compartments following herpes simplex virus infection. /. Virol. 68: 988-1001.

Saka, Y. and M. Yanagida. 1993. Fission yeast cut5+, required for $S$ phase onset and $M$ Phase restraint, is identical to the radiation-damage repair genc rad4+. Cell 74: 383-393.

Salminen, A and P.J. Novick. 1989. The Sec 15 protein responds to the function of the GTP binding protein, $\operatorname{Sec} 4$, to control vesicular traffic in yeast. /. Cell. Biol. 109: 1023-1036.

Savitsky, K., A. Bar-Shira, S. Gilad, G. Rotman, Y. Ziv, L. Vanagaite, D.A. Tagle, S. Smith, T. Uziel, S. Sfez, M. Ashkenazi, I. Pecker, M. Frydman, R. Harnik, S.R. Patanjali, A. Sim- mons, G.A. Clines, A. Sartiel, R.A. Gatti, L. Chessa, O. Sanal, M.F. Lavin, N.G.J. Jaspers, A. Malcolm, R. Taylor, C.F. Arlett, T. Miki, S.M. Weissman, M. Lovett, F.S. Collins, and Y. Shiloh. 1995. A single ataxia telangiectasia gene with a product similar to PI-3 kinase. Science 268: 1749-1753.

Schwob, E., T. Bohm, M.D. Mendenshall, and K. Nasmyth. 1994. The B-type cyclin kinase inhibitor $\mathrm{p}^{51 \mathrm{SI}}$ controls the G1 to $S$ transition in S. cerevisiae. Cell 79: 233-244.

Sclafani, R.A. and W.L. Fangman. 1984. Yeast gene CDC8 encodes thymidylate kinase and is complemented by herpes thymidine kinase gene TK. Proc. Natl. Acad. Sci. 81: 5821 5825.

Siede, W., A.S. Friedberg, and E.C. Friedberg. 1993. RAD9 dependent $\mathrm{Gl}$ arrest defines a second checkpoint for damaged DNA in the cell cycle of Saccharomyces cerevisiae. Proc. Natl. Acad. Sci. 90: 7985-7989.

Smith, S.A., P. Kumar, I. Johnston, and J. Rosamond. 1992. SCM4, a gene that suppresses mutant cdc4 function in budding yeast. Mol. \& Gen. Genet. 235: 285-291.

Sorger, P.K. and A.W. Murray. 1992. S-phase feedback control in budding yeast independent of tyrosine phosphorylation of p34 cd.28. Nature 355: 365-368.

Stern, D.F., P. Zheng, D.R. Beidler, and C. Zerillo. 1991. Spk1, a new kinase from $S$. cerevisiae, phosphorylates proteins on serine, threonine, and tyrosine. Mol. Cell. Biol. 11:9871001.

Tomkinson, A.E., N.J. Tappe, and E.C. Friedberg. 1992. DNA ligase I from Saccharomyces cerevisiae: Physical and biochemical characterization of the CDC9 gene product. Biochem. 31: 11762-11771.

Vallen, E.A. and F.R. Cross. 1995. Mutations in RAD27 define a potential link between $\mathrm{Gl}$ cyclins and DNA replication. Mol. Cell. Biol. 15: 4291-4302.

Weber, L. and B. Byers. 1992. A RAD9 dependent checkpoint blocks meiosis of cdc13 yeast cells. Genetics 131: 55-63.

Weinert, T.A. and L.H. Hartwell. 1988. The RAD9 gene controls the cell cycle response to DNA damage in Saccharomyces cerevisiae. Science 241: 317-322.

. 1990. Charactcrization of RAD9 of Saccharomyces cerevisiae and evidence that its function acts posttranslationally in cell cycle arrest after DNA damage. Mol. Cell. Biol. 10: 6554-6564.

. 1993. Cell cycle arrest of $c d c$ mutants and specificity of the RAD9 checkpoint. Genetics 134: 63-80.

Weinert, T.A., F.L. Kiser, and L.H. Hartwell. 1994. Mitotic checkpoint genes in budding yeast and the dependence of mitosis on DNA replication and repair. Genes \& Dev. 8: $652-665$.

Zakian, V.A. 1995. ATM-related genes: What do they tell us about functions of the human gene. Cell 82: 685-687.

Zheng, P., D.S. Fay, J. Burton, H. Xiao, J.L. Pinkham, and D.F. Stern. 1993. SPK1 is an essential S-phase-specific gene of Saccharomyces cerevisiae that encodes a nuclear serine/ threonine/tyrosine kinase. Mol. Cell. Biol. 13: 5829-5842.

Zhou, Z and S.J. Elledge. 1993. DUN1 encodes a protein kinase that controls the DNA damage response in yeast. Cell 75: 1119-1127. 


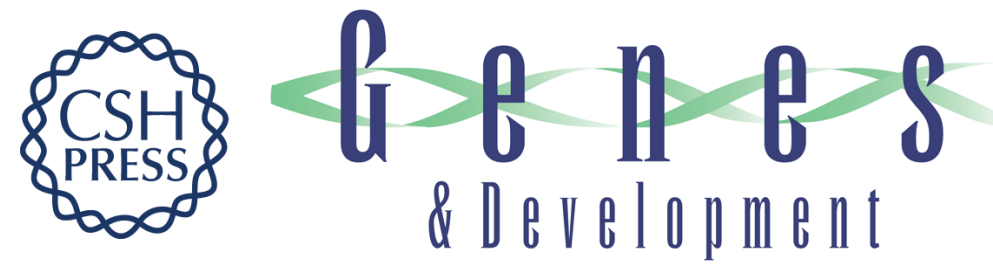

\section{Spk1/Rad53 is regulated by Mec1-dependent protein phosphorylation in DNA replication and damage checkpoint pathways.}

Z Sun, D S Fay, F Marini, et al.

Genes Dev. 1996, 10:

Access the most recent version at doi:10.1101/gad.10.4.395

References This article cites 49 articles, 22 of which can be accessed free at:

http://genesdev.cshlp.org/content/10/4/395.full.html\#ref-list-1

License

Email Alerting

Service

Receive free email alerts when new articles cite this article - sign up in the box at the top right corner of the article or click here.

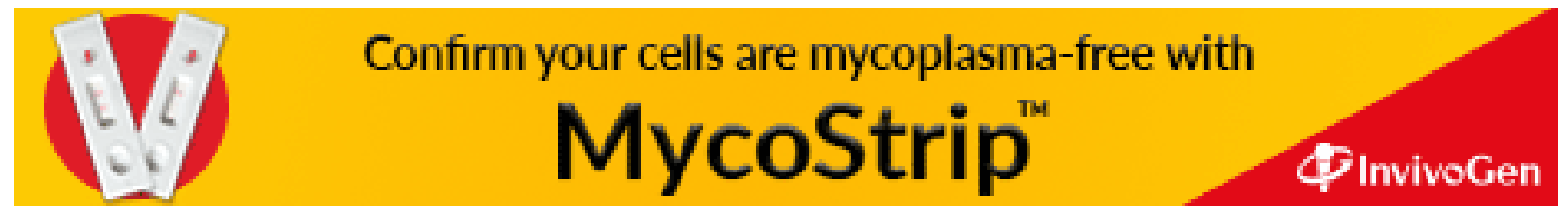

